\title{
Modeling the Flow of Crude Oil in Cracked Pipeline
}

\section{Kavi K. Kamal' ${ }^{1}$, Jafar A. ALI², Dara K. khidhir ${ }^{3}$}

${ }^{1}$ Petroleum and Energy Engineering Department, Sulaimani Polytechnic University, Sulaymaniyah, Iraq

2,3 Department of Petroleum Engineering, Koya University, Koya, Erbil, Iraq

Corresponding Author1: Kavi K. Kamal

Sulaimani Polytechnic University, Qirga, Wrme Street, 327/76, Sulaymaniyah, Iraq

E-mail: eng.kavi8@gmail.com, Phone Number: +(964) 7731496363

Article Info
Volume 7, Issue 4
Page Number: 226-233
Publication Issue :
July-August-2020

Article History

Accepted : 13 Aug 2020

Published : 19 Aug 2020

\section{ABSTRACT}

The form of transportation of energy from the sources to the consumers is the concern of the researchers across the world, this is due to the consequences upon the failures. Some of these failures causing economical losses and environmental damages. Both are worth to be investigated and studied to reduce the risks and losses. In this paper the effects of cracks in pipelines has been investigated, it is found that the crack is causing the decrease in pressure. Several pipes were used in the experiment, one without crack and the rest with different crack size. The pressure drop in the area around the crack (named crack zone) was bigger in the up and down stream zones. Computational fluid dynamics CFD package ANSIS (Fluent) was used in the analysis and the results presented. Because the fluid used in the research is crude oil, so the paper is mainly for the benefit of the oil and gas industries and the pipeline designers and manufacturers.

Keywords : Crude oil; Pipeline, Cracks, Pressure drop, CFD.

\section{INTRODUCTION}

Process of crude oil transportation is petroleum has become one of the most important sources of energy we have. Every day people use hundreds of products that are derived from oil, but this source of energy mostly has been known as an efficient fossil fuel in the transportation industry (Romero, 2017). Pipelines are one of the form of energy transportation used widely It has been shown that oil and gas pipeline networks are the most economical and safest mean of transporting crude oils and they fulfill a high demand for efficiency and reliability (Adegboye, Fung, \& Karnik, 2019).). When pipeline transport mode is used for crude oil, flow conditions depend on the rheological characteristics of the hydrocarbon phase. Laminar or turbulent flow regime can be found depending on the apparent shear viscosity (Benziane, \& Liazid, 2011). The fluctuating pressure drop in fluctuating laminar pipe flow has been derived. For turbulent flow, the problem is too complicated, it is still under consideration (Gao, zhen, et al, 2010). As liquids and gases are transported through the pipeline, the energy loss due to the friction between the fluid 
transported and the surface of the pipe will lead to a pressure drop (Orasheva, J.,2017). In practice, due to the process of crude oil in pipe flow, with the inner wall of pipeline caused by friction, along the pipeline pressure is reduced, to reduce the pressure will be converted into friction heat and fluid inside the pipeline heating (Cai, et al, 2018).

The pressure drop of a fluid is due to the variation of kinetic and potential energy of the fluid and that is due to friction on the walls of the flow channel (Hamad, et al, Z. 2017). The friction between the fluid particles in a pipe does cause a slight rise in fluid temperature as a result of the mechanical energy being converted to sensible thermal energy. But this temperature rise due to frictional heating is usually too small to warrant any consideration (Hadush, 2004). It is important to look for the other issues lead to the pressure drop in pipelines such as pipe failure. The causes of the failures are either intentional (like vandalism) or unintentional (like device/material failure and corrosion) damages, leading to pipeline failure (Adegboye, Fung, \& Karnik, 2019). This is resulting in irreversible damages which include financial losses and extreme environmental pollution, particularly when the leakage is not detected in a timely way. The causes of pipelines leaks can be classified to operational, structural, unintentional, and intentional. The operational class includes all leaks due to operations with oil/gas pipeline; equipment failure. The class of structural problems includes failures in pipelines as explosion, etc. The unintended damage is often caused by construction workers in nearby duct. Intentional damage can be caused by terrorist attacks and sabotage (Araújo, et al, 2014). Some of them divided the leaks in pipelines in two classes based on the amount fluid loss. One, leak by breaking the pipe occurs frequently, but it is dangerous due to the amount of product spilled in the vicinity of the leak. However, these disruptions are easy to detect because they are accompanied by pressure losses and volumetric differences. Class two is leakage of small proportions small leaks around 5 liters per hour are difficult to detect due to their sizes and can cause large losses of products to get noticed (Araújo, Neto, \& Lima, 2013). The large leaks are mainly occurred due to fractures in the pipeline. In addition to the environmental and economic impacts, this cause a noticeable drop in pressure of the fluid pass through. Many studies are available investigating the pressure drop in pipe, the pressure drop due to fracture is the most. (Al-khomairi, 2015) discuss transient flow and developed a technique to measure fluctuating differential pressures with high fidelity. In the current research the effects of cracks in the pipeline is investigated. This research paper provides a numerical analysis for the purpose of determining the impacts of cracks on the rate of oil flow and it is pressure drop in the pipe line system. To achieve this paper, diversified methods have been applied as a feasibility studies.

\section{METHODS AND MATERIAL}

This paper based on reviewing different articles from many international journals related to the impacts of cracked pipes and its consequences on the pressure drop (Pascal) and its discharge of the oil. For simulation purpose, a model was used which consists of a $2 \mathrm{~m}$ length cracked steel pipe in different shapes and geometries with internal diameter of $20 \mathrm{~mm}$ and outer diameter of $25 \mathrm{~mm}$. The same model with the same dimensions has been applied with no cracks. The obtained results were compared and tabulated in the next sections. A CFD package ANSYS software (Fluent Application) has been utilized to simulate the crude oil specifications and pipeline geometries as shown in the figures (1). Many empirical formulas and equations such continuity, momentum and energy have been applied for obtaining some parameters and determining many variables such as Reynolds number for identifying the types of flow. 
The results provided by the ANSYS were compared with the theoretical analysis.
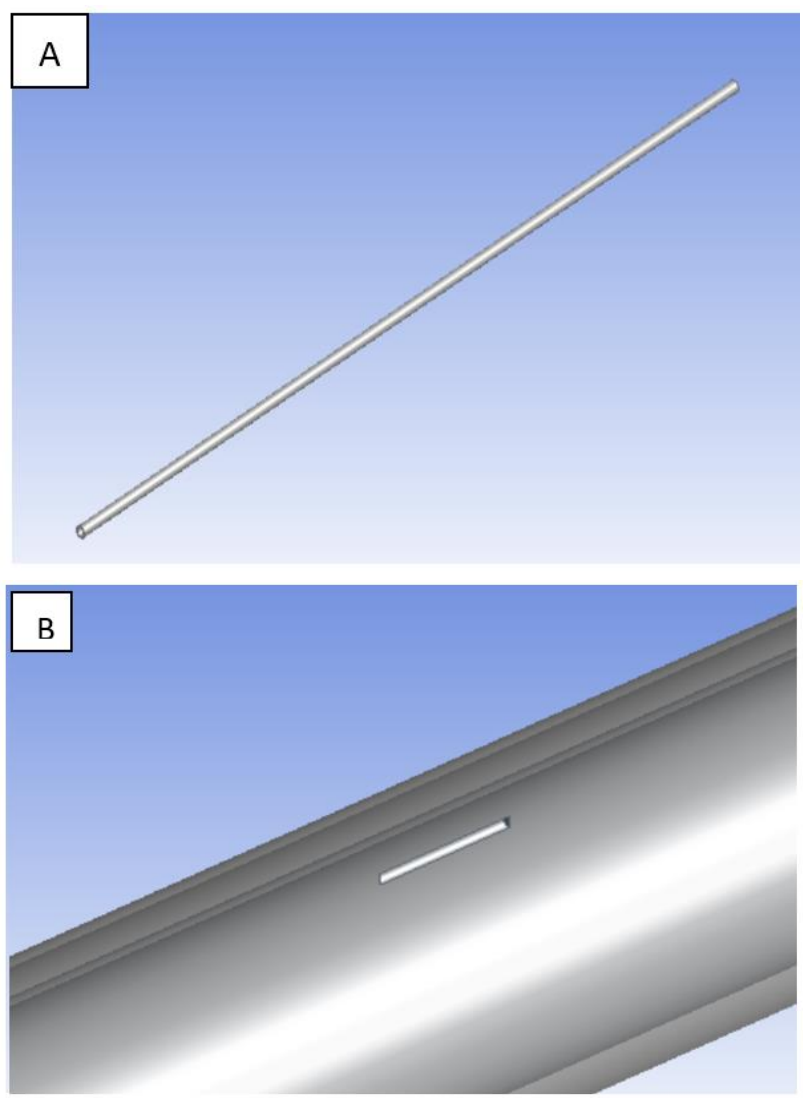

Figure 1: (A) Pipe without crack.

(B) Pipe with crack.

\section{EXPERIMENTAL SETUP}

As shown in the figure 2, the set up consists of the two tanks A and B. Tank A is set up at higher level than tank B. The outlet in the tank $A$ is at the same level of inlet of tank B. The tanks are connected by a pipe with length of 2 meter and outside diameter of $25 \mathrm{~mm}$ as shown in the figure $3 \mathrm{a}$ and the cracked pipe shown in figure $3 \mathrm{~b}$. The pipe is made from carbon steel. Steel is an important engineering material which serves a wide range of industrial applications. It is used amongst others in petroleum production and refining, marine applications, petrochemicals and polymer production and synthesis, construction equipment, chemical processing, mining and transmission pipelines (Usman, \& Okoro, 2015).
The tank A is followed by a valve for controlling the pressure gauge and flow meter is arranged to estimate the discharge of the liquid in the pipe. Then, three pressure gauges are connected to the pipe and setup sequentially for reading the pressure differences at different points such as calculating pressure in the upstream zone and crack zone which is located at 140 $\mathrm{cm}$. The final gauge is located at the other end of the pipe for computing the pressure in the downstream.

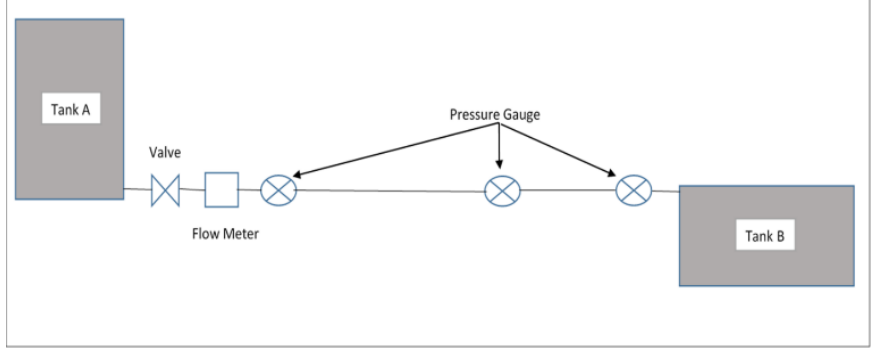

Figure 2. Experimental setup.

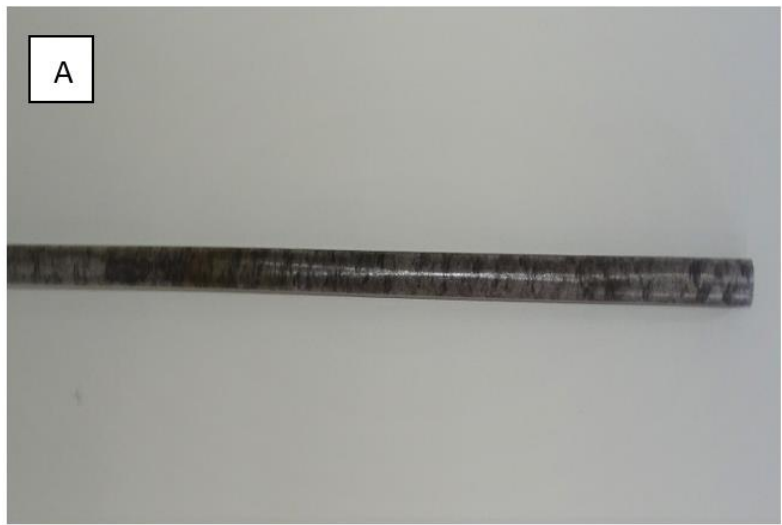

B

Figure 3. (A) Carbon steel pipe.

(B) Cracked carbon steel pipe 


\section{THEORETICAL ANALYSIS}

ANSIS program is among the platforms was used to simulate the data for analyzing the dimensions and finding out the consequences of the cracks on each parameter such as, the pressure drop and flow rate in $\left(\mathrm{m}^{3} / \mathrm{s}\right)$ of the oil in the modelling pipe. It has been presented that different sizes of pipes were investigated for both conditions the cracked pipes and pipes with no cracks. After that during the initial drawing of pipe geometry it has been illustrated that the size of the mesh was fine relevant center and high smoothing, the minimum size of grade is $29202 \mathrm{~m}$, the maximum grade face size was equal to $292.02 \mathrm{~m}$ and the maximum grade size is $584.03 \mathrm{~m}$, as shown in the figure 4 .

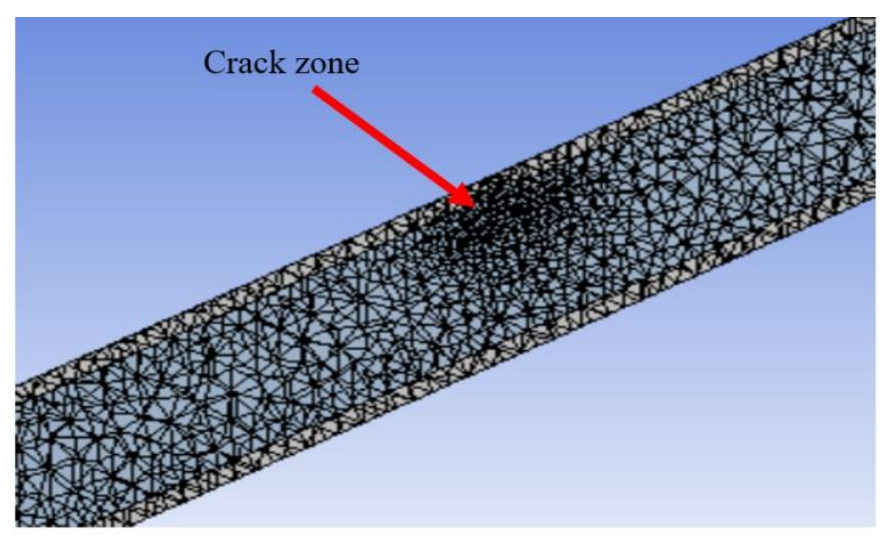

Figure 4: Mesh of the crack pipe.

Then after setting up the programmer all the physical properties of the crude oil have been entered to the software. The physical properties of the crude oil were including density, enthalpy, specific heat and viscosity were empirically measured at the laboratory and they were $\left(841 \mathrm{~kg} \backslash \mathrm{m} 3,74100 \mathrm{j} \backslash \mathrm{kg}, 1.96\right.$ at $20^{\circ} \mathrm{C}$ and $0.003704 \mathrm{~kg} \backslash \mathrm{m} . \mathrm{s})$ respectively. The velocity was 0.2 $\mathrm{m} \backslash \mathrm{s}$ at $290 \mathrm{k}$, the section area is $0.000314 \mathrm{~m}^{2}$ and the pressure is 16500.42 Pascal. The accuracy and precision of the CFD software to simulate the data are depending on the number of iterations. The dense mesh and large number of iteration lead to better results. The pipe with no cracks needed 226 iterations as compared with a larger number of iterations for the cracked pipe which was approximately 10000 iterations. The software has also calculated the pressure by momentum conservation equation (Akhlaghi, Taherkhani, \& Nouri, 2020). Finally, it has been determined precisely that the size of the crack was $0.0005 \mathrm{~m}$ by different length show the table 1 .

Table 1: Cases Studies

\begin{tabular}{|c|c|c|}
\hline Pipe case & Width of the $\operatorname{Crack}(\mathrm{m})$ & Length of the crack $(\mathrm{m})$ \\
\hline Case 1 & No Crack & No crack \\
\hline Case 2 & 0.0005 & 0.01 \\
\hline Case 3 & 0.0005 & 0.05 \\
\hline Case 4 & 0.0005 & 0.125 \\
\hline Case 5 & 0.0005 & 0.175 \\
\hline Case 6 & 0.0005 & 0.3 \\
\hline Case 7 & 0.0005 & 0.35 \\
\hline Case 8 & 0.0005 & 0.4 \\
\hline Case 9 & 0.0005 & 0.475 \\
\hline
\end{tabular}

\section{RESULTS AND DISCUSSION}

Based on the calculations presented by computational fluid dynamics software (CFD) investigation to determine the size of the crack pipe, it is indicated to deduce the flow pattern through the diverse sizes of crack by means of pressure, pressure drop and velocity parameters. All the cases of static pressure information documented by the pressure transducer presented in (figure 5). The results of this paper are confirming that in the first case which the pipes have no crack they require low pressure in comparison with the other circumstances in which the pressure started in around (135.79 Pascal) and gradually escalates to approximately (160 to 161.7) Pascal. These results are demonstrating that more pressure are required to the pipes having cracks for flowing in the pipe and vice versa low pressure is needed for the compact pipes with no cracks. As there has been no 
velocity at the end points of the pipe, the pressure for both cracked and no-cracked pipes was equal to zero.

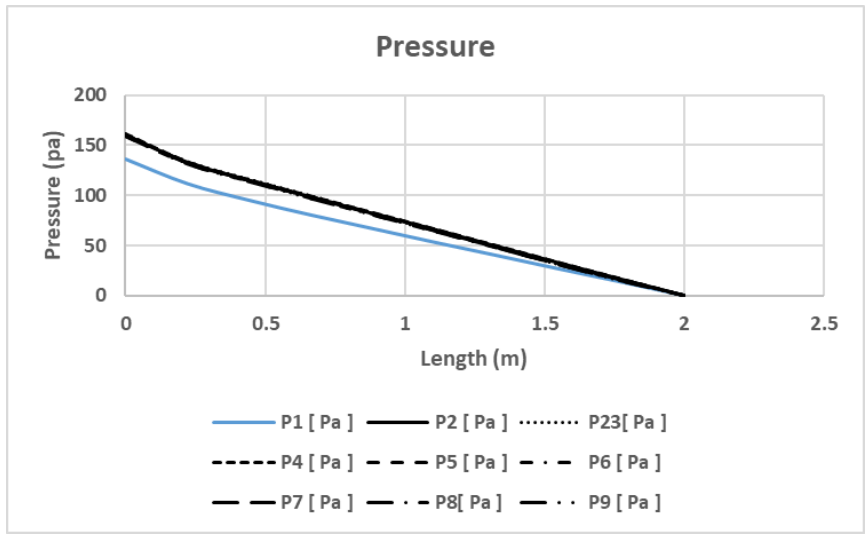

Figure 5. Pressure for $2 \mathrm{~m}$ pipe length.

As can be observed from (figure 6), the presented pressure drop has a smaller amount in the first case without crack and the pressure drop at the end is (13.295 Pascal) however for the other circumstances the pressure drop is fluctuating from [15.5 to 16.3 Pascal]. As the flow in the pipe altered intermittently, the pressure drop in the experimentation pipe fluctuated (Gao, zhen, et al, 2010). Consequently, due to the frictional forces between the fluid particles in a pipe results in a slight rise in fluid temperature as a result of the mechanical energy being transformed to functional thermal energy. Nonetheless, this temperature increase as a result of friction heating is extremely small that is not necessary to any deliberation (Hadush, 2004). And occasionally the coarseness of the pipe makes the variation in the pressure drop but this vacillation between these circumstances is very small therefore it can be unconsidered in the calculations.

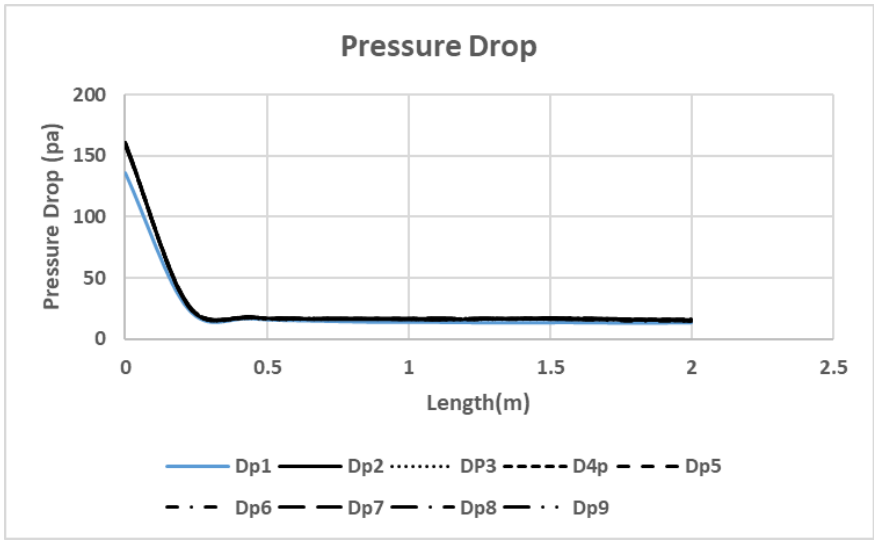

Figure 6. Pressure drop for $2 \mathrm{~m}$ pipe length.

On the other hand, the velocity of the fluid in the pipe with respect to the pressure head were determined by applying the post-processed in the ANSYS CFD-Post, a package included in the software, in order to deliver a better investigation of the study. It has been illustrated that the velocity is varying according to the points in longitudinal section of the pipe. Figure (7) demonstrates the velocity computations along the pipeline axis and in the outlet section. As can be seen from the chart below, the velocity of the fluid is starting from $0.2 \mathrm{~m} / \mathrm{s}$ at the beginning of both cracked and non-cracked pipes; this implies that the velocity profile is equivalent in all the circumstances simulated in this experiment. Although, the peak velocity has been emerged in the compactness pipes (pipes with no cracks), the figure for the cracked pipes are slightly smaller than the velocity of the not-cracked pipe, this refers to the change in pressure head and roughness of the pipes which has been a principal constraint for increasing the velocity of the pipes. 


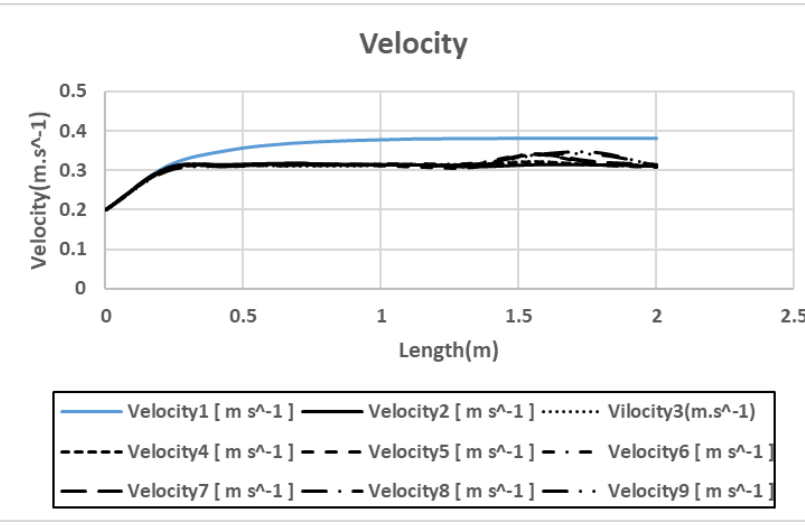

Figure 7. Velocity for $2 \mathrm{~m}$ pipe length.

It can be observed from (figure 8) below the data zone for pressure drops has been classified in to three zones including upstream, cracked zone and downstream. Moreover, the pressure drop has a disproportional relationship with the crack lengths. It has been observed that initially the maximum pressure drop occurs while the pipe has small cracks, whereas, the figure of pressure drops has declined with happening cracks in the pipe.

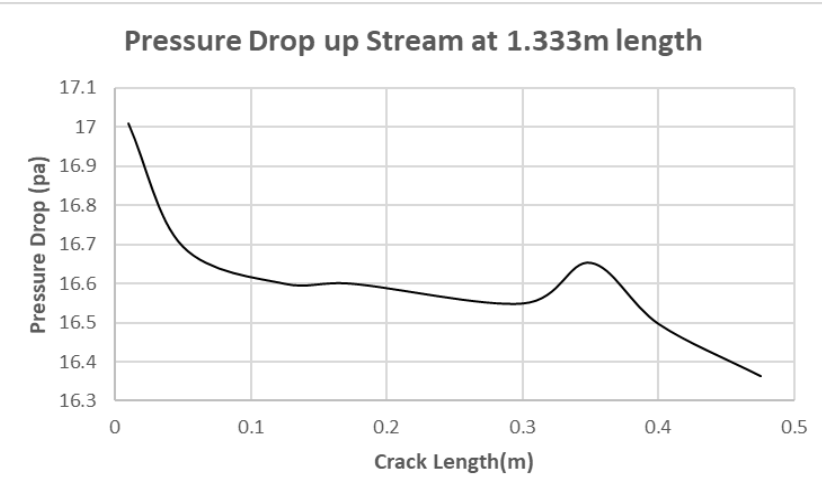

Figure 8: Pressure drop in upstream at $1.3334 \mathrm{~m}$ length However, there has been a sudden fluctuation in the $0.3 \mathrm{~m}$ crack length; the figure has dropped down again to the minimum pressure drop at the end of the pipe. More importantly, there has been a significant variation between the crack length and pressure drop in the pipe. Similarly, while the crack length reached to the maximum, the greatest pressure drop has been revealed which was approximately $16.35 \mathrm{~Pa}$ at the $0.47 \mathrm{~m}$ crack length of the pipe. These results confirm that there is a disproportional connectedness between the crack-length and pressure drops in the pipe for the entire zones.

On the other hand, according to the obtained results from (figure 9), there has been a profound difference in the crack zones at point $1.5556 \mathrm{~m}$ length, there has been a proportional relationship between the crack length and pressure drop as shown in the figure below. Furthermore, it has been observed that in the lengths between $(0.01 \mathrm{mto} 0.5 \mathrm{~m})$ there has been a dramatic increase in the pressure drops which has raised from around 16.4 to nearly $16.7 \mathrm{~Pa}$.

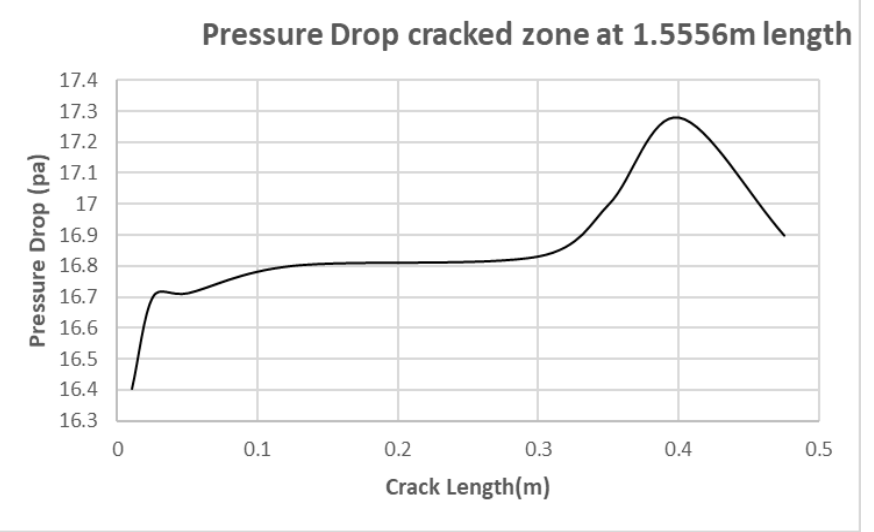

Figure 9: Pressure drop in cracked zone at $1.5556 \mathrm{~m}$ length.

Nevertheless, in the last zone which has been shown in the (figure 10) above, which is known as downstream part of the pipe, two portions have been revealed in this calculation. The first part in which the crack length is smaller than $30 \mathrm{~cm}$, the pressure drop is declined as the crack length increased. Conversely, as shown in the figure below, the figure of pressure drop has raised dramatically for the lengths greater than $30 \mathrm{~cm}$. The obtained results from figure (10) confirm that this region is known as the crack zone region in the pipe. The pressure drop is increasing directly as the crack length upgrading. It has been demonstrated that the maximum pressure drop can be attained while the crack length approached from approximately $0.5 \mathrm{~m}$. from this perspective, this research has confirmed that the 
pressure drop is principally depending on the size and dimensions of the crack in the pipe.

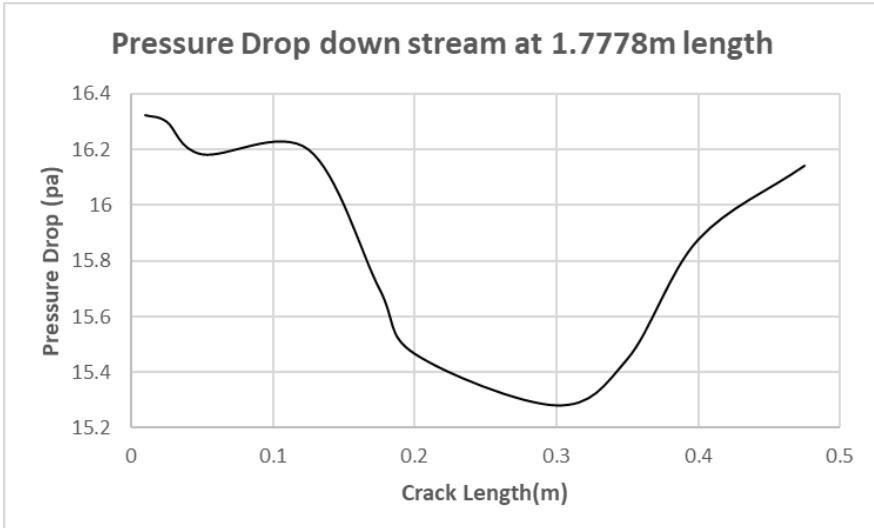

Figure 10. Pressure drop in downstream at $1.7778 \mathrm{~m}$ length.

\section{VI.CONCLUSION}

In this research work it is reached to a fact that the crack in the pipelines will cause problem to the flow of the fluid. As the pressure drop and the discharge of crude oil in the pipelines are two important issues in the oil and gas industries. The work concluded that the pipelines that have cracks are less efficient to transport the oil from one point to another as compared to pipes with no cracks. There is a pressure drop in the crack zone even where no leaks occur.

\section{REFERENCES}

[1]. Adegboye, M. A., Fung, W., \& Karnik, A. (2019). Recent Advances in Pipeline Monitoring and Oil Leakage Detection Technologies: Principles.

[2]. Akhlaghi, M., Taherkhani, M., \& Nouri, N. M. (2020). Study of Intermittent Flow Characteristics Experimentally and Numerically in a Horizontal Pipeline. Journal of Natural Gas Science and Engineering, 103326.

[3]. Al-khomairi, A. (2015). Use of the steady-state orifice equation in the computation of transient flow through pipe leaks USE OF THE STEADYSTATE ORIFICE EQUATION IN THE
COMPUTATION OF TRANSIENT FLOW THROUGH PIPE. (August).

[4]. Araújo, M. de V., Neto, S. R. de F., \& Lima, A. G. B. de. (2013). Theoretical Evaluation of TwoPhase Flow in a Horizontal Duct with Leaks. Advances in Chemical Engineering and Science, 03(04), 6-14.

[5]. Araújo, M. D. V., Rodrigues, S., Neto, D. F., Gilson, A., Lima, B. De, Daylane, F., \& Luna, T. De. (2014). Hydrodynamic Study of Oil Leakage in Pipeline via CFD. 2014(2).

[6]. Benziane, M. M., \& Liazid, A. (2011). Crude-Oil Flow Modelling in Pipeline Conditions. 275284.

[7]. Cai, H., Zhao, L., Chen, X., Chen, X., Guan, T., Wang, J., Lv, B., \& Li, S. (2018). Optimization of Temperature Drop Formula for Annular Gathering Pipeline in High Water Cut Oil Region of Central Hebei Province. 21-26.

[8]. Gao, P. zhen, Liu, T. hao, Yang, T., \& Tan, S. chao. (2010). Pressure drop fluctuations in periodically fluctuating pipe flow. Journal of Marine Science and Application, 9(3), 317-322.

[9]. Hadush, T. (2004). Flow in pipes Flow in pipes. Fluid Mechanics, 1-25.

[10]. Hamad, F. A., Faraji, F., Santim, C. G. S., Basha, N., \& Ali, Z. (2017). Investigation of pressure drop in horizontal pipes with different diameters. International Journal of Multiphase Flow, 91, 120-129.

[11]. Orasheva, J. (2017). The Effect of Corrosion Defects on The Failure of Oil and Gas Transmission Pipelines: A Finite Element Modeling Study. UNF Graduate Theses and Dissertations.

https://digitalcommons.unf.edu/etd/763

[12]. Romero, O. J. (2017). Influence of oil leakage in the pressure and flow rate behaviors in pipeline Influence of oil leakage in the pressure and flow rate behaviors in pipeline. (September). https://doi.org/10.21712/lajer.2017.v4.n1.p17-29 
[13]. Usman, A. D., \& Okoro, L. N. (2015). Mild steel corrosion in different oil types. International Journal of Scientific Research and Innovative Technology, 2(2), 9-13

\section{Cite this article as :}

Sh Kavi K. Kamal, Jafar A. ALI, Dara K. khidhir, "Modeling the Flow of Crude Oil in Cracked Pipeline ", International Journal of Scientific Research in Science and Technology (IJSRST), Online ISSN : 2395-602X, Print ISSN : 2395-6011, Volume 7 Issue 4, pp. 226-233, July-August 2020. Available at doi : https://doi.org/10.32628/IJSRST207468

Journal URL : http://ijsrst.com/IJSRST207468 